\title{
Disasters and Public Health Emergencies-Current Perspectives in Preparedness and Response
}

\author{
Amir Khorram-Manesh ${ }^{1,2, *(1) \text { and Frederick M. Burkle Jr. }}{ }^{3}$ \\ 1 Institute of Clinical Sciences, Department of Surgery, Sahlgrenska Academy, University of Gothenburg, \\ 40530 Göteborg, Sweden \\ 2 Department of Research and Development, Swedish Armed Forces Centre for Defense Medicine, \\ 42676 Göteborg, Sweden \\ 3 Harvard Humanitarian Initiative, T.H. Chan School of Public Health, Harvard University, \\ Boston, MA 02115, USA; skipmd77@aol.com \\ * Correspondence: amir.khorram.manesh@gmail.com or amir.khorram-manesh@surgery.gu.se; \\ Tel.: +46-707-722-741
}

Received: 7 October 2020; Accepted: 15 October 2020; Published: 16 October 2020

Disasters and public health emergencies are inevitable and can happen anywhere and anytime. However, they can be mitigated and their impacts can be minimized by utilizing appropriate measures in all four different phases of disaster management, i.e., mitigation and prevention, preparedness, response, and recovery. Several factors are crucial for achieving successful disaster management. In the mitigation and preparation phase, all risks should be reviewed and new ones should be added and analyzed carefully to propose proper solutions and plans. In the preparedness phase, the ability and knowledge of each organization and all individuals in the management system should be tested and evaluated to ensure good readiness in responding to an emergency. Furthermore, plans should be available at all levels of the emergency chain of action to cope with all issues in the response and recovery phases [1,2]. This Issue of Sustainability aimed to cover emergency and public health crisis management from a multiagency perspective, by discussing lessons learned, introducing new ideas about flexible surge capacity, and showing the way it can practice multiagency collaboration.

One important part of mitigation and prevention is to analyze the potential risks in society. Risks are dynamic and may change due to social and political changes. In her paper, Posluszna reports the prognostic view on the ideological determinants of violence in the radical ecological movement [3]. She argues that ecologically motivated violence that manifests itself in animal and environmental rights has been increasing. Along with the multiplicity of the methods used (arson, food poisoning in supermarkets, destruction of equipment, and attacks with the use of incentivized devices), this type of violence should be considered as a dynamic and difficult-to-grasp phenomenon (eco-terrorism) that can endanger our society and its inhabitants and has the potential to create new public health emergencies and disasters. Starting with the ecosystem, there are other important natural resources and environmental factors, such as water, that are essential for the management of disasters and public health emergencies. In their report, Bross et al. discuss emergency preparedness planning in the water supply [4] and emphasize that various scenarios such as floods, power failures, or even a pandemic can influence the supply and provision of water. They present a newly developed composite indicator system to assess the status of emergency preparedness planning and compare two weighting methods. The results show that there is a need for action in emergency preparedness planning at several levels, especially in the area of risk analysis and the evaluation of measures.

Preparedness enables staff to act confidently, but do they act efficiently? Goniewicz et al. try to answer this question by using a questionnaire to assess the relationship between hospital and staff preparedness and disaster response efficiency among healthcare providers in Poland. They reported that the evaluation of the preparedness and effectiveness of disaster response is essential for finding 
and removing possible gaps and weaknesses in the functioning and effective management of a hospital during mass-casualty incidents [5]. Thus, preparedness is crucial, but how prepared are we? From this perspective, the emergency staff's "perception of preparedness is particularly important, since they influence risk assessment and risk communication to the public, policy agendas, and implementation of policies and initiatives [6-8]".

In their report, Sultan et al. assessed the perceived disaster readiness of emergency nurses in the southern part of Saudi Arabia by using a self-assessment questionnaire. The participating nurses reported good perceived knowledge in almost all investigated aspects of the theoretical dimensions, but perceived weaknesses in practical dimensions of emergency management and difficulties in assessing their own efforts. Simulation exercises, including theoretical and practical aspects of emergency management, were suggested to continuously examine and strengthen nurses' knowledge, skills, and abilities [9]. These results are concordant with those reported by Diakakis et al., who also found a correlation between knowledge and perception of risks and readiness with personal characteristics of participants, such as education level, qualification, age, years in service, etc., whereas, handling the everyday issues, practices and processes was correlated with their positions in the hierarchical chain [10]. Although prepared and knowledgeable, are healthcare providers really willing to risk their lives to work during disasters and public health emergencies? The willingness of healthcare providers to stay and fight in an emergency and the impact of social support on job engagement and retention intention was examined by Kim et al., among nurses struggling in the continuing scenes of the current pandemic (COVID-19). Data collected in this study showed that nurses' job engagement and job retention intention were high, depending on their age and work experience. However, in terms of factors related to the Covid-19 pandemic, the group with experience in nursing patients infected with COVID-19 and nurses working in COVID-19 divisions had low job-retention intentions. They could also identify possible differences in job engagement and job-retention intention due to the category and type of social support. These results suggest that social support should be provided strategically to ensure nurses' job retention [11].

Preparedness should be enhanced by multiagency exercises and training, and in all environments, i.e., water, air, and land. Carlström et al. [12] investigated differences between on-shore and off-shore exercises and aimed to compare findings from trained emergency staffs' perceptions of the impact of exercises. Data collected from surveys showed that collaboration is a predictor for some of the items in learning, and learning was a predictor for some of the items in utility. There was, however, a stronger covariation between collaboration, learning, and utility in the off-shore exercises than in the on-shore. This result is interesting, as it points out the potential of cultural differences in different organizations as well as professional attitudes and legal restrictions in the outcome of training and exercises. Karlsson et al. [13] aimed to explore the collaborative learning process of exercise organizers from the rescue service, mining companies, the emergency medical service, a training company, and academia. They used the theory cycle of expansive learning to the material consisting of documents from collaboration meetings and full-scale exercises to make tools in collaboration with the participants. These tools were further examined and tested during collaboration meetings and were implemented during full-scale exercises. The exercise organizers believed that this process led to organizational development and a better understanding of the other organizations' perspectives. Consequently, a tentative model for developing the learning process of exercise organizers was developed. Dealing with collaboration as an important factor in the teamwork, Sørensen et al. [14] conducted a study to test whether there is a relationship between exercise participation and perceived levels of learning and utility by using an online survey. Data were collected from participants in a two-day, full-scale, wildland-fire collaboration exercise in southeastern Norway, using an already existed instrument, the collaboration, learning, and utility (CLU) scale. According to their findings, joint evaluations, improvising, and testing of new and alternative strategies across sectors are important when exercises are constructed. Finally, Steiro et al. [15] presented lessons learned from a case study in the Norwegian armed forces to exemplify the importance of preparedness and multiagency 
collaboration. The paper aimed to investigate the structure for learning and the learning outcomes from a paper exercise based on multiagency collaboration and point to potential benefits for crisis leadership and management in civil organizations by using the participant observation model in one exercise and a questionnaire in the following exercise to measure outcomes. They identified five management principles for interaction under unforeseen conditions: (1) develop a pedagogical view for the organization, (2) facilitate and train using processes for complementary process development, (3) develop a precise and common language, (4) train the organization in concurrent learning, and (5) develop tolerance and mutual respect. These reports all indicate the need for collaboration and coordination, not only among various agencies but also among different states and nations. Current pandemic shows that all nations and states can be influenced, and indicates a need for a collaborative and coordinated approach to healthcare, and economic and social issues resulting from a disaster [16,17].

Besides preventive measures and proper preparedness, the response to the disaster and public health emergency management requires both structural and non-structural resources. Glantz et al. emphasize the concept of flexible surge capacity and the need for extra resources in an expanding emergency to increase local and regional surge capacity in a flexible manner [18]. They investigated the use of alternative care facilities within a community and found interest and ability in the primary healthcare centers; veterinary and dental clinics; and schools, sports, and hotel facilities, to participate in such a system, either by receiving resources and/or drills and exercises. Limiting factors for potential participation in this response system consisted of a varying lack of devices, healthcare materials, competences, clear organizational structure, legal support, medical responsibility, and sufficient funding. Raidla et al. [19] argue that an alternative care facility can also be organized within or near to a hospital to improve the flexibility needed in peacetime as well as during disasters. They investigated this concept by examining how the establishment of an urgent care center (UCC), i.e., a secondary emergency department (ED), co-located and in close collaboration with an ED, can influence the outcome of treatment in terms of length of stay, time to a physician, and use of medical services. The results showed reduced waiting times at the UCC, both in terms of length of stay, and time to a physician. They concluded that creating a primary care-like facility in close proximity to the hospitals may not only relieve overcrowding of the hospital's EDs in peacetime but may also provide an opportunity to create a flexible resource to be used during disasters and public health emergencies. A flexible surge capacity needs trained leadership and other personal resources. Phattharapornjaroen et al. [20] searched for alternative leadership among emergency physicians (EP) in Thailand [17]. Using an established method for training collaboration, two training courses were arranged for over 50 Thai EPs, who were divided into three teams of prehospital, hospital, and incident command groups. Three scenarios of a terror attack, along with a bomb explosion, riot, and shooting, and high building fire, were presented, and the participants' performance was evaluated regarding their preparedness, response, and knowledge gained. The results obtained in this study showed that Thai EPs' perceived ability in command and control, communication, collaboration, coordination, and situation assessment improved in all groups systematically. New perspectives and innovative measures were presented by participants, which improved the overall management on the final day. They conclude that tabletop simulation exercises can be used to increase the perceived ability, knowledge, and attitude of Thai EPs in managing major incidents and disasters, providing alternative leadership as part of the concept of a flexible surge capacity response system.

Finally, the current Covid-19 pandemic has shown the importance of the public-private partnership (PPP) during both the response and the recovery phases of disasters and public health emergencies. In these phases, there is the possibility of widespread project failures and constrained budgets, which makes governments search for ways to prioritize projects in the need of relief and bolster post-pandemic recovery plans. To meet this need, Baxter et al. conceptualized a triage system for PPP programs based on five categories: (1) projects without a need for economic stimulus (blue); (2) projects experiencing minor economic/financial losses (green); (3) projects needing temporary/stop-gap support or restructuring (yellow); (4) projects unable to survive without significant economic relief (red); and 
(5) projects that cannot survive, even with government intervention (black) [21]. They also stress the importance of launching and sustaining a central crisis command to support PPP triage decisions and encourage PPP stakeholders to collectively craft win-win solutions for post-pandemic recovery efforts.

Altogether, this Issue offers new insights into emergency and public health crisis management from a multiagency perspective and allows discussion about new potential risks; lessons learned; and the introduction of new concepts such as flexible surge capacity, and shows some new aspects of practicing multiagency collaboration before, during, and after disasters and public health emergencies.

Funding: The research received no external funding.

Conflicts of Interest: The authors declare no conflict of interest.

\section{References}

1. Burkle, F.M., Jr. Disaster management, disaster medicine and emergency medicine. Emerg. Med. Aust. 2001, 13, 143-144. [CrossRef] [PubMed]

2. Khorram-Manesh, A. Flexible Surge Capacity—Public heaklth, public education, and disaster management. Health Promot. Prespect. 2020, 10, 175-179. [CrossRef] [PubMed]

3. Posluszna, E. A prognostic view on the ideological determinants of violence in the radical ecological movement. Sustainability 2020, 12, 6536. [CrossRef]

4. Bross, L.; Wienand, I.; Krause, S. Batten Down the Hatches-Assessing the status of emergency preparedness planning in the German water supply sector with statistical and expert-based weightng. Sustainability 2020, 12, 7177. [CrossRef]

5. Goniewicz, K.; Goniewicz, M. Disaster preparedness and professional competence among healthcare providers: Pilot study results. Sustainability 2020, 12, 4931. [CrossRef]

6. Donovan, A.; Eiser, J.R.; Sparks, R.S.J. Scientists' views about lay perceptions of volcanic hazard and risk. J. Appl. Volcanol. 2014, 3, 1-14. [CrossRef]

7. Boholm, Å.; Prutzer, M. Experts' understandings of drinking water risk management in a climate change scenario. Clim. Risk Manag. 2017, 16, 133-144. [CrossRef]

8. Beck, U. Risk Society: Towards a New Modernity; Sage: Newcastle upon Tyne, UK, 1992.

9. Sultan, M.H.S.; Khorram-Manesh, A.; Carlström, E.; Sørensen, J.L.; Al Sulayyim, H.J.; Taube, F. Nurses' readiness for emergency and public health challenges-The case of Saudi Arabia. Sustainability 2020, $12,7874$. [CrossRef]

10. Diakakis, M.; Damigos, D.G.; Kallioras, A. Identification of Patterns and Influential Factors on Civil Protection Personnel Opinions and Views on Different Aspects of Flood Risk Management: The Case of Greece. Sustainability 2020, 12, 5585. [CrossRef]

11. Kim, Y.J.; Lee, S.Y.; Cho, J.H. A study on the job retention intention of nurses based on social support in the Covid-19 situation. Sustainability 2020, 12, 7276. [CrossRef]

12. Carlström, E.; Magnussen, L.I.; Kristiansen, E.; Berlin, J.; Sørensen, J.L. Inter-Organizational exercises in dry and wet context-Why do maritime response organizations gain more knowledge from exercises at sea than those on shore. Sustainability 2020, 12, 5604. [CrossRef]

13. Karlsson, S.; Saveman, B.I.; Hultin, M.; Eklund, A.; Gyllencreutz, L. Expansive learning process of exercise organizers: The case of major fire incident exercises in underground mines. Sustainability 2020, 12, 5790. [CrossRef]

14. Sørensen, J.L.; Halvorsen, C.; Aas, J.P.W.; Carlström, E. "Share Your Tools"—A utility study of a Norwegian Wildland-Fire collaboration exercise. Sustainability 2020, 12, 6512. [CrossRef]

15. Steiro, T.J.; Torgersen, G.E. Preparedness and multiagency collaboration-Lessons learned from a case study in the Norwegian Armed Forces. Sustainability 2020, 12, 7240. [CrossRef]

16. Khorram-Manesh, A.; Carlström, E.; Hetelendy, A.J.; Goniewicz, K.; Carter, B.C.; Burkle, F.M. Does the prosperity of a country play a role in COVID-19 outcomes? Disaster Med. Public Health Prep. 2020, 1-10. [CrossRef] [PubMed]

17. Goniewicz, K.; Khorram-Manesh, A.; Hetelendy, A.J.; Goniewicz, M.; Naylor, K.; Burkle, F.M. Current response and management decisions of the European Union to the COVID-19 outbreak: A review. Sustainability 2020, 12, 3838. [CrossRef] 
18. Glantz, V.; Phattharapornjaroen, P.; Carlström, E.; Khorram-Manesh, A. Regional Flexible Surge Capacity-A flexible response system. Sustainability 2020, 12, 5984. [CrossRef]

19. Reidla, A.; Darro, K.; Carlson, T.; Khorram-Manesh, A.; Berlin, J.; Carlström, E. The outcomes of establishing an Urgent Care Centre in the same location as an emergency department. Sustainability 2020, 12, 8190. [CrossRef]

20. Phattharapornjaroen, P.; Glantz, V.; Carlström, E.; Dahlén Holmqvist, L.; Khorram-Manesh, A. Alternative leadership in Flexible Surge Capacity-The perceived impact of tabletop simulation exercises on Thai emergency physicians' capability to manage a major incident. Sustainability 2020, 12, 6216. [CrossRef]

21. Baxter, D.; Casady, C.B. A Coronavirus (COVID-19) Triage framework for (Sub) National Public-Private Partnership (PPP) Programs. Sustainability 2020, 12, 5253. [CrossRef]

Publisher's Note: MDPI stays neutral with regard to jurisdictional claims in published maps and institutional affiliations.

(C) 2020 by the authors. Licensee MDPI, Basel, Switzerland. This article is an open access article distributed under the terms and conditions of the Creative Commons Attribution (CC BY) license (http://creativecommons.org/licenses/by/4.0/). 